\title{
Increasing Access to Clean Cooking: The Practicality of Pay-Go in Promoting Adoption of Bottled Gas in Kinondoni, Dar Es Salaam, Tanzania
}

\author{
Editha M. Ndunguru \\ Institute of Development Studies, Mzumbe University, Mzumbe, Tanzania \\ Email: 3ndunguru@gmail.com, endunguru@mzumbe.ac.tz
}

How to cite this paper: Ndunguru, E.M. (2021) Increasing Access to Clean Cooking: The Practicality of Pay-Go in Promoting Adoption of Bottled Gas in Kinondoni, Dar Es Salaam, Tanzania. International Journal of Clean Coal and Energy, 10, 41-58. https://doi.org/10.4236/ijcce.2021.103003

Received: July 1, 2021

Accepted: August 27, 2021

Published: August 30, 2021

Copyright () 2021 by author(s) and Scientific Research Publishing Inc. This work is licensed under the Creative Commons Attribution International License (CC BY 4.0).

http://creativecommons.org/licenses/by/4.0/ (c) (i) Open Access

\begin{abstract}
The majority of the population in developing countries have limited access to clean energy. To increase access to clean energy, the governments and other stakeholders have been working hard to create enabling environments for their adoption and utilization. For the household cooking sector, technological innovations such as improved biomass fuels, improved biomass cookstove, solar cooking, biogas and recently bottled gas service have been or are being deployed to scale up clean cooking. Nevertheless, a good number of the innovations intended for upscaling clean cooking in developing countries have failed to meet the desired goals due to limited support from the national governments or the international community. Pay-Go is among the recent innovations in the East African region intended for promoting the use of bottled gas (liquefied petroleum gas-LPG). This study evaluates the practicality of Pay-Go innovation on bottled gas, popularly known as Pay-as-you-Cook. Specifically, the article examines the evolution of Pay-as-you-Cook, its execution, usefulness and challenges; and its implications on household energy sector development. The study was conducted in Kinondoni Municipality, Dar es Salaam, Tanzania between 2018 and 2020. The study used both qualitative and quantitative approaches. Purposive and non-random sampling techniques were used in selecting respondents. Purposive sampling was used to identify key informants while snowball sampling was used to find household respondents. Information was gathered from KopaGas (Pay-as-you-Cook innovator) headquarter-Kinondoni Morocco; and from Pay-as-you-Cook clients in Kinondoni Moscow, Mkwajuni and Hananasif. Methods of data collection involved semi-structured interviews and observation. Instruments of data collection included interview guides and observation checklists. Data analysis was accomplished with Nvivo 12. Findings show that Pay-as-you-Cook innovation was intended for promoting bottled gas adoption mainly to low-income households. The innovation was discovered to be convenient to many low- income households as it enabled them to use bottled gas for cooking without necessarily climbing the economic ladder. Yet, the innovation presents several challenges which are doubtful to its practicality.
\end{abstract}




\section{Keywords}

Clean Cooking, Practicality, Adoption, Pay-Go, Bottled Gas

\section{Introduction}

At times the emphasis is being given on utilisation of modern clean cooking fuels. Access to cleaner energy sources and technologies can contribute to adaptation and mitigating climate change, combating desertification and forest degradation and lessening the serious health problems especially for women and children through decreasing the use of traditional biomass for energy [1]. Unfortunately, households in most developing countries are highly dependent on traditional fuels for cooking, heating and lighting, which have negative impacts on health and the environment [2]. To scale up the utilization of clean fuels for household cooking, public and private institutions, non-government organizations as well as individuals have been working hard to create enabling environments for clean cooking. Technological innovations such as improved biomass fuels, improved biomass cookstove, solar cooking, biogas and recently bottled gas service are some of the innovations which had/have been or are being deployed to scale up clean cooking.

There is no doubt that innovations accelerate socio-economic development and societies' wellbeing. Through innovation, societies can boost the economy in a variety of ways such as improving agricultural productivity, strengthening manufacturing industries, increasing access to clean and efficient energy and improving health, water and sanitation services. The literature presents that technological innovation plays a crucial role in determining whether or not the growth and development process in society is inclusive. Inclusive growth is the development that has a positive impact on living standards and results in better quality jobs (particularly for the poor), has the potential to reduce environmental pollution, increase the efficiency of resource use and improve health [3]. Technological development is significant for all those countries which aspire to support economic development [4]. When fostering competitiveness, productivity and job creation, innovation is considered as an essential force for starting and fueling the engine of growth.

In developing countries, innovation has become a catalyst to poverty alleviation and a breakthrough to economic independence [5]. The innovations emerging from within these countries have the potential to provide answers to many of the socio-economic challenges such as poor agricultural yield, financial services, health care systems, transport services, water and sanitation and clean energy development to mention a few. Currently, innovations can boost economic growth and facilitate the realization of the 2030 global agenda on Sustainable Development.

So far, innovations have assisted many African countries to improve their economies and still there is a great possibility for rapid and inclusive growth. Even 
though, some of the innovations have been ineffective due to various reasons such as inadequate research and development ( $R \& D)$, lack of funding, lack of policy backup and/or poor stakeholder involvement.

Currently, innovations particularly in Africa have been dominated by digital technology especially through the use of mobile phones and internet service [6]. The power of digital technology has manifested in many ways from access to banking services, bill payment and utility services. A good example is the mobile money service. With this invention, people with mobile phones can deposit, transfer, or withdraw funds without even having bank accounts. The innovation was first introduced in South Africa and the Philippines, but later two East African countries, Kenya and Tanzania experienced a rapid rise in mobile money usage, all in the mid-2000s. As of 2015, more than 222 million mobile money accounts were registered across Africa, and African countries account for more than half of all mobile money services worldwide [7]. Digital technology has also knocked the door to the household energy sector aiming to increase access to, availability and affordability of clean energy.

It is acknowledged that energy has become an integral part of human life [8]. The relationship between energy and human well-being is shown in the relationship between per capita energy use and the Human Development Index (HDI) [9] [10]. It is therefore assumed that innovation in developing countries would be directed more towards sectors that would contribute to human development, among them is energy. Energy is needed by households, institutions, manufacturing and agricultural sectors to mention some, to stimulate production, generate income and enhance development to the community [8]. In the household, energy is needed essentially for cooking. Different ways of cooking which include boiling, poaching, grilling and steaming require heat energy to make the food palatable, to kill harmful germs and to increase its taste. Conventionally, cooking energy would be generated from wood, plant residual and animal dung (traditional fuels). With time, types of energy used are diversified; utilisation of energy is becoming more intensive, and more complex appliances are coming into use. At times the emphasis is being given to the utilisation of modern clean fuels. Developing, enabling and promoting access to cleaner energy sources and technologies can contribute to adaptation and mitigating climate change, combating desertification and forest degradation and lessening the serious health problems especially for women and children through decreasing the use of traditional biomass for energy [1].

For quite some time technological innovations have been deployed in the energy sector, aiming to increase access to clean energy services. For household cooking arrangements, electricity, natural gas and liquefied petroleum gas are highly prioritised to reduce the proportion of the population relying on traditional biomass fuels. Of the three mentioned energy sources though, liquefied petroleum gas is predominantly well suited to domestic cooking in most of the developing countries because cooking with electricity or natural gas is largely impractical [11] [12]. As opposed to the former, LPG (bottled gas) can be scaled- up relatively 
quickly due to lower infrastructure investments needed and ease of transportation and storage [13] [14]. In many developing countries, electricity supply is unreliable, electric cookstove devices are relatively expensive and electric tariffs are too high for the majority to afford. As for natural gas, even if they are endowed with the resource, governments do not have adequate capital to invest in infrastructure, and sometimes poor urban planning hinders piped gas infrastructure development [15]. Distributing natural gas to consumer homes is exceptionally expensive with a prolonged period of payback ratio.

\section{Literature}

So far, LPG is used by almost 3 billion people worldwide [16]. In most of the middle-income countries and among the wealthy households in developing countries, LPG has already replaced traditional fuels exclusively or for selected cooking tasks [12]. Over the past two decades, households in developing regions indicated a sharp increase in LPG consumption. For instance, between 1990 and 2011, household LPG consumption had an annual average increase of $9.6 \%$ in non-Organisation of Economic Cooperative Development Asia, 5\% in Africa, $3.4 \%$ in the Middle East and $1.5 \%$ in Latin America.

All over the world, the adoption of LPG has been a process largely associated with financial expenditure [17]. The common assumption presented by the energy ladder model advocates income as the major determinant of energy adoption, elucidating that households tend to abandon traditional dirty fuels and adopt more sophisticated fuels with increased income [18] [19]. The concept behind this is that LPG adoption requires a significant amount of money to cover initial investment or upfront costs and maintenance or running costs. This suggests that the economic status of the individual, household or community would positively or negatively affect the LPG adoption process. At the lowest level, low-income households have a low probability of using LPG while high-income households have a greater probability of using it as they can afford the costs.

By and large, scientific studies provide that the adoption of LPG has the potential to reduce the number of problems related to biomass utilisation. It is simply linked to overall human wellbeing and development by offering a wide range of socio-economic and environmental benefits directly or indirectly [20] [21].

The Tanzanian government has been advocating the adoption of LPG for household cooking to reduce utilisation of biomass fuel realising that the use of biomass fuel contributes to extensive deforestation [22]. In 2009 for example, Tanzania was reported to have the highest proportion of deforestation in Africa (33.0\%) attributed to charcoal production [23] [24]. A World Bank report on the charcoal situation in Tanzania informs that about 100,000 - 125,000 hectares of annual forest loss are accredited to unsustainable charcoal production, imposing high pressure on the existing natural biomass resources, and higher deforestation and forest degradation levels [7]. Through the National Energy Policy, the government calls for the utilisation of LPG as an alternative to biomass energy to re- 
duce pressure on forest resources. LPG is considered the best option to replace charcoal [22].

Stakeholders of the energy sectors are determined to promote LPG usage, essentially in the urban areas where almost all household cooking fuels are purchased. To make it widely available, accessible and affordable the stakeholders have been creating an enabling environment via different strategies to promote adoption.

Kinondoni is among the urban centres in Tanzania whose majority of their populations rely exclusively on purchased fuels. Rapid population growth, extensive urbanisation and geographical location significantly affect types of fuel to be used, fuel availability and consumption. Kinondoni Municipality has high household cooking fuel consumption compared to other municipalities in Dar es Salaam, the commercial city of the country. This municipality constitutes the largest population size, high population growth rate and rapid urban sprawl. In 2012 Kinondoni Municipality had a total population of $1,775,049$. With an average annual growth rate of 5\%, in 2016 Kinondoni was estimated to have 3,217,884 people [25]. In 2013, Kinondoni recorded the highest charcoal consumption in the city whereby more than 20 tonnes were sold by whole sellers monthly [26]. This could probably be higher than any other municipality in the country.

Different interventions have been undertaken to address cooking energy challenges. Among them is the dissemination of clean cookstoves and the utilisation of improved charcoal. However, the increasing need for clean fuels has propelled technological innovations to encourage the adoption of clean cooking solutions. Having LPG as the readily available modern cooking energy at present, Kopagas Company invented LPG smart metering service branded as Pay-as-you-Cook. Pay-as-you-Cook is digital technology founded by two individuals; one Tanzanian and one Mexican. The local invention has helped to remove affordability barriers on LPG especially by medium and low-income households [27]. The technology uses smart meters to compute the consumption of gas from a cylinder and it allows customers to use mobile money services to purchase quantities of gas according to their budgets. Smart metres contain specific identification numbers which customers use to recharge their cylinders through mobile money services (Figure 1). 


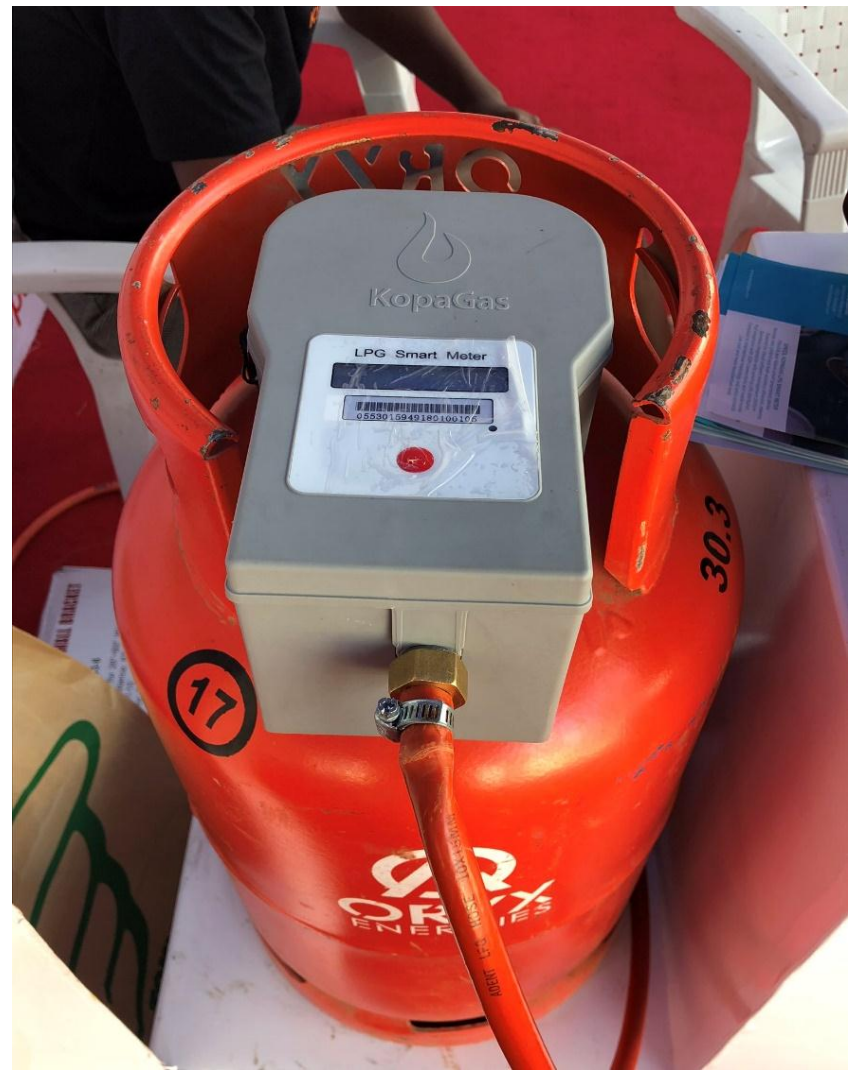

Figure 1. LPG smart-metre fixed to the gas cylinder. Photo by: Ndunguru, 2019.

The use of smart meters is said to address challenges presented by the conventional way of LPG usage, mainly cylinder acquisition and refilling charges. Nevertheless, Pay-as-you-Cook has barely penetrated to reach the targeted populations as expected despite its existence of about six years in the market. This paper evaluates the practicality of Pay-as-you-Cook innovation in promoting the adoption of LPG for household cooking activities.

\section{Methodology}

The study was carried out in Kinondoni ${ }^{1}$ Municipality, Dar es Salaam. The choice of the study area was influenced by the deployment of Pay-as-you-Cook (smart metering) service which was launched in the municipality. Kinondoni was one of the three municipalities that constituted Dar es Salaam City, before 2016 (in 2016 Kinondoni was split into two municipalities namely Kinondoni and Ubungo). Kinondoni is located at latitude $6^{\circ} 47^{\prime} 0^{\prime \prime} \mathrm{S}$ and longitude $39^{\circ} 16^{\prime} 0^{\prime \prime} \mathrm{E}$ and covers an area of 531 square kilometres 28, 29, 30 Kinondoni borders Ilala district to the South, Coast region to the West and South-West and the Indian Ocean to the North [28] [29] [30]. Two main roads which feed Dar es Salaam City from upcountry; Morogoro and Bagamoyo/Ali Hassan Mwinyi Roads, enter via Kinondoni.

The study used purposive sampling techniques to select respondents. The study

${ }^{1}$ Old Kinondoni Municipality, before its split into two municipalities; (new) Kinondoni and Ubungo. 
involved six respondents; two KopaGas founders and four Pay-as-you-Cook clients. The study applied a descriptive research design. Descriptive research is used to obtain information concerning the current status of the phenomena and to describe "what exists" concerning variables or conditions in a situation [31]. The study was highly qualitative but constituted few quantitative elements. Content analysis was used to analyse the data and the results were presented in texts and photos.

\section{Results and Discussion}

\section{Evolution of Pay-as-you-Cook}

Pay-as-you-Cook is a recent innovation deployed by KopaGas Company to enable low and middle-income households to switch away from traditional biomass such as charcoal to LPG as clean and efficient cooking fuel. This inventive way of LPG consumption uses advanced measuring devices referred to as intelligent or smart metres. A smart meter is a successor of the traditional metering device which used Automated Meter Readings (AMR) system that permitted utilities to remotely read the consumption records and basic information from the customers' site [32]. With this one-way communication system, AMR could not run additional applications. This challenge provoked utilities to improve the technology to an Advanced Metering Infrastructure (AMI) or Smart Metering [33]. Smart meters use machine-to-machine technology, including the use of the internet and mobile phones to access utility services [34] [35].

\section{Liquefied Petroleum Gas Smart Metres}

Technology development has led to the discovery of smart meters which can be used to detect and compute Liquefied Petroleum Gas (LPG) consumption. LPG smart metering service was firstly launched in Tanzania for a try-out [36]. The pilot project was executed in the year 2014 in Kinondoni municipality, Dar es Salaam. In 2015 the UK Development for International Development (DfID) acknowledged KopaGas efforts to promote clean energy utilisation, hence the GSM Innovation Grand to KopaGas founders. This was a great move to the innovation and it encouraged the founders to invest more in improving and disseminating it.

Traditional LPG uptake largely replicates the energy ladder hypothesis that households will shift to a more sophisticated energy career as their income increases [37]. On the contrary smart metering (Pay-as-you-Cook) does not essentially require increased income but a few appliances, mainly the cookstove. Payas-you-Cook can promote LPG adoption while skipping the energy ladder theory. Low and middle-income households can afford gas without necessarily climbing the economic ladder (Figure 2).

Using the Global System for Mobile Communications Association (GSMA); Mobile for Development Utilities programme, customers use mobile money services to purchase quantities of gas that fit their budget. During an interview with 


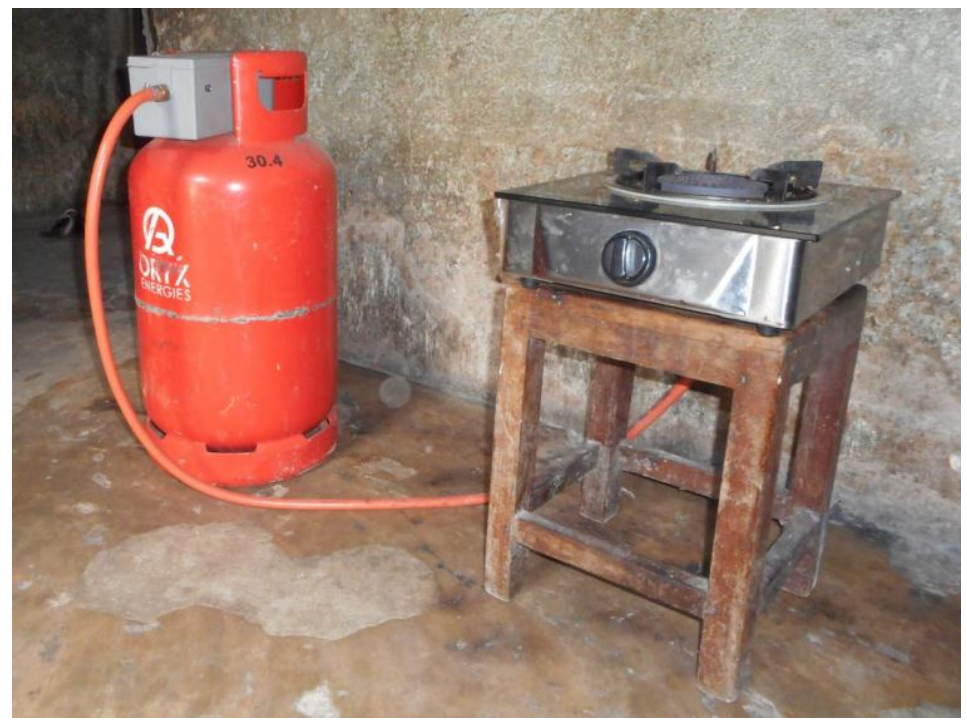

Figure 2. Pay-as-you-Cook service in a low-income household in the study area. Photo by: Ndunguru (2019).

one of the co-founders, it was explained that a household needs only 15,000 TZS (\$6.50) as an upfront fee to get a liquefied petroleum gas (LPG) cooking kit that includes a cylinder fitted with a smart meter. The gas supply is unlocked by mobile phone payments and the meter monitors consumption, feeding back data via the Internet of Things (IoT). It is more like Tanesco's LUKU system where electricity consumers can use their mobile phones to buy tokens to access the service.

Pay-as-you-Cook innovation has attracted many people in Kinondoni Municipality since it reduces the burden of initial costs and refilling charges which obstruct the poor to adopt LPG. It takes as little as TZS 1000 (USD 0.43) to purchase cooking gas. As of late 2018, KopaGas had distributed about 2000 smart metres and is projected to have distributed about 10,000 smart meters by the end of 2019 . However, the diffusion of Pay-as-you-Cook has been too slow to meet the rapidly growing demand of the target population. KopaGas co-founder declared that the sluggish diffusion of the innovation is a result of low investment. It is said that smart metering service requires large investment for infrastructure development and distribution. Unfortunately, the company cannot supply a sufficient number of meters due to limited finances.

By August 2019 only 3500 households were registered for the service. The number of registered clients was too far below the target and the company still had insufficient funds to invest. This situation force KopaGas founders to search for new investors to rescue their technology. Early 2020, KopaGas's branded technology was sold to Circle Gas Limited, a UK holding company based in Nairobi, Kenya. The deal is thought to be the largest-ever pure private equity investment in the clean cooking technology sector. Through a world-class team, experienced in the downstream distribution of LPG, Circle Gas aims to expand the existing business in Tanzania and launch in Kenya in 2020 to facilitate energy access for the mass market via the scale-up of the innovation [38] [39]. Circle Gas has to im- 
prove the innovation and disseminate further to reach more populations in the East African region.

\section{Practicality of Pay-as-you-Cook}

Results show that Pay-as-you-Cook innovation is practical in promoting clean cooking in Kinondoni and other urban areas. It was discovered during the study that technology is among the pathways to achieving Sustainable Development Agenda, in particular, Sustainable Development Goal 7; to ensure access to affordable, reliable, sustainable and modern energy for all [40]. The usefulness includes reduction of upfront costs, fuel affordability, comfortability and financial gains. Observation shows that a significant proportion of the urban residents distinguish smart metering from conventional bottled gas service and traditional biomass fuels. Respondents acknowledged several benefits stemming from Payas-you-Cook as presented in Figure 3.

A detailed analysis revealed that Pay-as-you-Cook can transform the household cooking sector in Kinondoni and Tanzania at large because it allows households with different income levels to use bottled gas for their domestic cooking need. Apart from the fore mentioned benefits, Pay-as-you-Cook addresses the following key areas of concern to the majority of the end-users especially low-income households.

\section{Upfront cost reduction}

Pay-as-you-Cook can help many poor households to switch to LPG. With Pa-as-you-Cook, customers may not necessarily have to pay for cylinder deposit and related accessories. According to KopaGas official, KopaGas gives the cylinder and related accessories to new customers on lease. A new customer is only required to buy a gas stove of his/her choice. The service has benefited more households by allowing them to easily adopt LPG as confirmed by customers themselves during the interview:

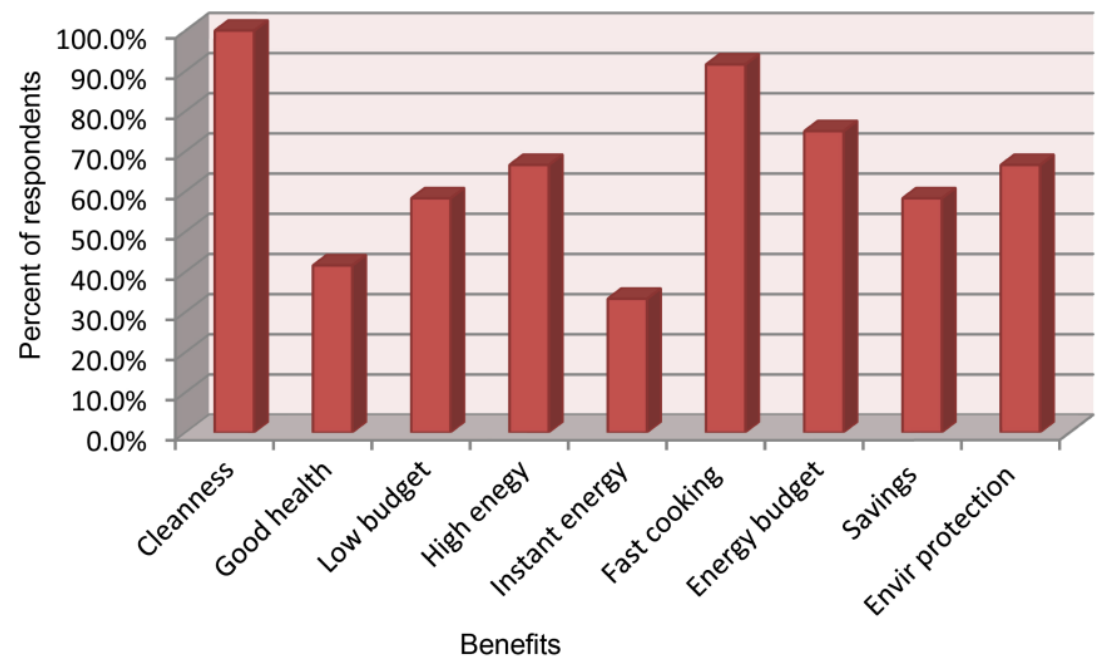

Figure 3. Benefits of LPG smart metering service according to end-users. Source: Ndunguru, field data, 2019.

"KopaGas has helped us very much. As for me, I never thought that one day I 
will use gas in my kitchen. Purchasing a gas cylinder and accessories with my little income was impossible, but after being informed about this service I didn't think twice. I registered and started using gas." (Service beneficiary, Kinondoni Hananasif; IDI-19th September, 2018)

An increase in the number of LPG users is evidence that more people are being registered for the service. Data from the field presents that, subscribers increased from 5 to 148 in the first eight months (Dec 2016-Aug 2017) [27]. The number of subscribers rose to more than 2000 in mid-2018. KopaGas projected that in the next 12 months there would be about 10,000 customers, the majority of whom would be those living below the poverty line.

High start-up cost is the principal factor hindering poor households to adopt LPG [41] [42]. During their study in Dar es Salaam, Alem and others [2], found out that 93 per cent of their sample households reported high start-up costs for LPG accessories as the main obstacle to their adoption. Many people would wish to use LPG as an alternative to charcoal but due to higher upfront costs, they have continued to rely on traditional biomass especially charcoal. Charcoal is more expensive than LPG, nevertheless, it remains to be the only choice for poor households just because it is sold in smaller quantitiesthey can afford with their subsistence income.

\section{Fuel affordability}

Pay-as-you-Cook service offers affordable prices even to people with limited financial capabilities. Research reports show that fuel costs are high that many people cannot afford [13]. It was discovered during the household survey that the reason for (some) people to stop using LPG even after paying the upfront cost, is high cylinder refilling price. Nevertheless, Pay-as-you-Cook gives charcoal users the opportunity to use LPG. The amount of money that buys charcoal can purchase a certain amount of gas. During the study, it was revealed that customers can obtain gas for as little as Tshs. 1000 (USD 0.45) the amount which buys a tin or heap of charcoal. Respondents declared that they recharge their gas with a small amount of money which would not buy gas under conventional way of LPG uptake.

"Usually I pay Tshs. 2000 to buy gas and the amount of gas purchased lasts for two days. If not for Pay-as-you-Cook I wouldn't afford gas." (Mama Asia, Kinondoni Hananasif; IDI-19th September 2018)

“After my husband passed away, I couldn't afford to use gas anymore because it was too expensive for me. My cylinder remained empty for more than two months and the stove started to decay. After I joined KopaGas things have changed. Even with 5000, I can buy gas. If I don't have any money, I can just call my children and ask them to send me at least 5000. I'm sure it would be not easy for them to send me 50,000 at once for cylinder exchange but 5000 is manageable". (Client who shifted from the traditional LPG uptake model to Pay-as-you-Cook service, Kinondoni Mkwajuni; IDI-26th September 2018) 


\section{Comfortability}

Pay-as-you-Cook customers comfortably access the fuel and get to observe consumption rate. Normally clients are supplied with gas through home delivery services. Kopagas delivers $15 \mathrm{~kg}$ cylinders with an unsold amount of gas. A cylinder with the unsold amount of gas is delivered to the customers and exchanged. KopaGas has its customer service agents located in different areas in Kinondoni. Among the areas are Mkwajuni, Hananasif, Kijitonyama, Mwananyamala, Mwenge and Salasala. The customer service agents supply gas and offer some technical services to nearby clients.

The technology also allows users to observe gas consumption rate and gas remainder since the smart meter has a screen that shows three important features; the battery level, the unused amount of money and gas consumption. These features allow clients to compute average gas consumption, hence adjusting themselves to their desired levels according to their budget. With a conventional LPG, model gas runs out unnoticed unless there is no blazing anymore. A client who once used the traditional model lamented that she noticed a rapid draining of gas in the cylinder but she could not know how it happens until she found strangers cooking in her kitchen.

"In the past gas consumption was so irregular. I had a $6 \mathrm{~kg}$ cylinder. Sometimes it lasted for a month, sometimes two weeks and sometimes less than that. I decided to investigate what was the problem. One day I went back home earlier than usual and found a stranger cooking her stuff in my kitchen. I questioned my house help and she confessed that she normally invites her friends to cook in my kitchen. I was so disappointed. Since I registered for Pay-as-you-Cook I have nothing to worry about because I know the average consumption and I can tell how much gas has been consumed." (FGD-August, 2018)

\section{Financial prosperity}

Financial prosperity may reveal itself in two different ways; income generation and income saving. The service provider, KopaGas generates income through service provision. Different from conventional ways of LPG uptake, KopaGas increases LPG customers' threshold, hence generating more profit through Payas-you-Cook service. The KopaGas co-founder admits that Tanzania is a healthy market for the business and it is expected that payback for the investment may not take too long. On the other hand, expansion of the service paves the way to the creation of employment in society. Some people are employed by the company while others work as agents. Also Oryx, Vodacom and Tigo benefit as co-partners of the service.

Individuals or households also benefit financially through savings because LPG is slightly cheap than charcoal. Hence, using gas instead of charcoal will save the extra amount of money that would be spent on charcoal. A female client affirmed that Pay-as-you-Cook has given her the capacity to save a certain amount of mon- 
ey previously used to buy charcoal.

"Previous I used to spend Tshs 2000 - 2500 for charcoal per day but with this service, I spend an average of Tshs. 1000. I save about Tshs. 1000 - 1500 every day. This money helps me cater for other needs including payments to the SACCOS." (Female client in Kinondoni FGD-August, 2018)

Another benefit of smart metering service is government revenue. KopaGas Oryx, Vodacom and Tigo do pay taxes and other fees according to the laws and regulations. As represented by household survey respondents, smart metering subscribers acknowledge several benefits of the service.

Despite its prospects in increasing access to clean fuel, a smart metering service meter is potentially burdensome as it may. Constitute high recharging costs compared to the traditional usage. On another hand, poor infrastructure may hinder smooth service provision but also influence the exclusion of some households.

Pay-as-you-Cook might be a little bit expensive to recharge compared to traditional refill. Although it seems to give price relief to low-income households, there can be some hidden costs that may not be easily detected by the customers. Like any other investor, KopaGas Company seeks to generate profit from the business. Recharging gas with smart metering service is expensive than the traditional model of supply. It was informed during in-depth interview that smart meters and gas cylinders are rented and payment is done gradually during gas recharge. It should be noted that plus mobile money services are also charged and all such expenses are to be covered by service beneficiaries. Unverified data from respondents maintain that Tshs. 1000 purchases $250 \mathrm{mg}(1 / 4 \mathrm{~kg})$ insinuating that $1 \mathrm{~kg}$ is sold at Tshs. 4000. With this amount, Pay-as-you-Cook customers are charged Tshs. 60,000 for a $15 \mathrm{~kg}$ cylinder while the traditional model customers are charged between Tshs. 48,000 - 50,000. Household survey data also show that majority of the service subscribers believe that it is too expensive to recharge with smart metering than the traditional uptake model except that it can be paid in small amounts. However, some believe it is cheaper while others consider it average.

\section{Challenges of Pay-as-you-Cook}

Like any other innovation, Pay-as-you-Cook encounters different challenges which slow down its diffusion. The challenges are manifested in both the supplier and consumers' sides. Among them are inadequate funding, poor infrastructure, high running cost, complexity and exclusion as discussed below.

\section{High investment cost}

Pay-as-you-Cook requires a large investment for infrastructure development and distribution as declared by one of KopaGas co-founders during the study. This led to the limited ability to disseminate the technology. Lack of capital suppressed the company's capacity to supply cylinders and meters. LPG accessories especially cylinders are too expensive to buy and that is the reason why cylinders are not sold but are rented. KopaGas relied on Oryx gas for cylinders and gas supply. To reduce the financial burden to the customer meters were also given on lease and payment was done through Pay-as-you-Cook. In this lending business, it took 
about 12 to 24 months to get the returns for the meter. KopaGas co-founders pleaded for government intervention to support the innovation through direct financing or reducing import duty on cylinders and meters. It was revealed that low investment is a major setback to the development and diffusion of innovation.

\section{Poor infrastructure and delayed services}

This challenge affects both the service provider and the customers. The majority of clients are from low-income clusters and larger proportions of these populations reside in unplanned settlement areas which have no proper physical address, impassable access roads and poor drainage systems. Customers living in such areas may encounter delayed services especially cylinder delivery. Service providers are also affected by poor infrastructure in that it takes too long to locate houses in unplanned areas. Sometimes additional costs are incurred because labourers have to be hired to take cylinders by foot through impassable roads or flooded areas where delivery vans cannot reach destinations. Kinondoni Moscow is among the areas with such inconveniences.

\section{Few customer service agents and shops}

KopaGas rely on agents to serve its clients who are dispersed in different locations. However, very few LPG retail shops are registered as KopaGas agents. In Hananasif ward, for example, only one agent was found. According to the 2012 population census, the ward has 9279 households on average. This is a very huge number to be served by only one agent. Widespread customer service centres may play a big role in information dissemination to prospective customers. A respondent from Kinondoni Moscow informed that her decision to adopt Payas-you-Cook was influenced by KopaGas advertisements.

High recharging costs

Although Pay-as-you-Cook gives price relief to low- and middle-income households by reducing upfront costs and refilling charges, few hidden costs may not be easily detected by the customers. Like any other private investors, KopaGas and Circle Gas Companies are profit-making companies. Recharging gas with smart metering service can be expensive than the traditional model of supply. From the information provided by KopaGas that smart meters and gas cylinders are rented (and rent is paid gradually through meter recharging), it is obvious that customers would pay the rent throughout the time of service. Mobile money services are also charged, thus increasing the expenses to be covered by end-users (customers). Unverified data from respondents maintain that Tshs. 1000 purchases $250 \mathrm{mg}(1 / 4 \mathrm{~kg})$ insinuating that $1 \mathrm{~kg}$ is sold at Tshs. 4000. With this amount, Pay-as-you-Cook customers are charged Tshs. 60,000 for a $15 \mathrm{~kg}$ cylinder while the traditional model customers are charged between Tshs. 48,000 - 50,000. Household survey data also show that majority of the service subscribers believe that it is too expensive to recharge with smart metering than the traditional uptake model except that it can be paid in small amounts.

\section{Complexity}

The equipment used for Pay-as-you-Cook relies on batteries to offer metering services. For the meter to function properly batteries have to be adequately charged. 
Electricity is the source of power for meter charging. Customers are advised to check the battery level every time before they ignite the gas stove. If the battery is too low, it has to be recharged first. Cooking with a low battery causes the meter to shut down and when it shuts down all the data is erased. Battery charge and durability are the technical pitfalls that are somewhat affecting the reliability of the service. The stability of the battery charge depends on the use; there is no distinct duration. Pay-as-you-Cook clients reveal that they recharge the battery almost every morning even if the battery is half full. Close to fifty per cent of the respondents report that they are concerned with the durability and reliability of the battery. Responding to that, KopaGas co-founder explained that the company took into consideration and was working hard to invent durable batteries. The latest battery edition (as of 2018) was made to last for about six months but during the study, it was still on trial.

Another challenging issue is the involvement of multiple actors in service provision. Since it depends on the Internet of Things (IoT), Pay-as-you-Cook involves several stakeholders which include KopaGas itself (smart meter expertise), Vodacom/Tigo (mobile money services) and Oryx (cylinder/gas supplies). Defect from any one of them may lead to poor or total failure of the service.

\section{Exclusion}

Because the meter battery has to be charged, Pay-as-you-Cook service seems to be excluding households with no grid electricity. Poorer households that form a large segment of the population that is not connected to electricity may not benefit from the service. KopaGas opened up that the challenge is being addressed by innovating solar batteries so that this group will also be able to subscribe. The service provider also explained that subscribers with high consumption rates are more preferred than the opposite. Large size households have high consumption rates because they frequently cook at home while small size households like singles and students have low consumption rates because they frequently eat out. This is a silent exclusion to potential consumers.

Many forces and factors hamper successful progress along innovation journeys, particularly for the clean energy sector and in developing countries like Tanzania [43]. One important point to note is that innovation requires extensive research and development to be improved or scaled up. Research and development bring about sector evolution through technology transfer, foreign investments and collaborations. In Tanzania, the Commission for Science and Technology $(\mathrm{COSTECH})$ is there to support individual researchers and research institutions to promote skills development and innovations that help to provide solutions to the problems faced by the community. Unfortunately, none of the co-founders opened up on whether there were any efforts made by KopaGas to contact COSTECH before selling the technology to a foreign investor. The innovation played a significant role in the development and strengthening of key components of the local innovation and entrepreneurship ecosystem [44]. Although Circle Gas is determined to continue with Pay-as-you-Cook services in Tanzania, the impact of the innovation in changing the local community's wellbeing might not be as high as if it 
would be locally based. Acquisition of KopaGas by local firms or government organisations would have more returns. An internal market can imply an increase in the standardisation of products and processes [45]. Handing the technology over to foreign (private) investors may or may not promote the diffusion and development of the technology domestically. There is also a possibility that it may pre-empty competition, slows down the improvement of the technology and the development of more efficient alternatives. Following the procurement of the technology by Circle Gas, most of the activities have been shifted to Nairobi, Kenya. This may affect the diffusion process in Kinondoni and Tanzania at large and delay the resulting benefits.

Research and Development ( R \& D) and innovation activities in many sustainable development-related technologies especially related to the environment are characterized by low investment and slow diffusion. Incentives for low carbon innovation are further weakened by real and perceived uncertainties about lack of clear direction and policy instruments.

It is also important to know that energy sector development needs the collaboration of various stakeholders such as the health sector, environment, forestry, policymakers, financial institutions and consumers. The involvement of multiple stakeholders is a very important element in promoting and improving innovations because it helps to identify opportunities and challenges as well as strengths and weaknesses. In Kenya for example, to support the private sector development infoDev engaged Kenya's Private Sector Alliance (KEPSA) and over eighty private firms working in climate and clean energy areas to understand local barriers hampering market growth and export potential [43].

\section{Conclusion}

Section 3.1.6 of the National Energy Policy enlightens about the utilisation of alternative energy sources to replace traditional biomass and minimise deforestation and environmental degradation (2015, NEP pg. 21). NEP outlines the need to explore possibilities for fuel switch to other forms of energy including LPG [22]. There can be varied possibilities such as natural gas, electricity, biogas, green charcoal, ethanol and solar energy. Of all these, LPG is relatively good for the urbanites because it does not need much effort to bring it into the market. The innovation of Pay-as-you-Cook has assured majority of charcoal consumers that they can cook with gas (LPG) even with their title budget, however, government intervention is highly needed to ensure that people from all income groups can afford clean fuels. The government has to make sure that the innovation is not commercialized so that the majority, particularly the poor can purchase LPG. To avoid commercialization of the innovation, the government should have intervened by endorsing Public-Private Partnership (PPP). The commitment of the government increases credibility on projects development and service delivery. It is important, therefore, for the KopaGas founders and the governments to ensure that the procured innovation is extensively diffused in Kinondoni and other urban centres in Tanzania to reduce biomass consumption and its associated consequences to 
bring about inclusive development.

\section{Conflicts of Interest}

The author declares no conflicts of interest regarding the publication of this paper.

\section{References}

[1] IPCC (2019) Climate Change and Land: An IPCC Special Report on Climate Change, Desertification, Land Degradation, Sustainable Land Management, Food Security, and Greenhouse Gas Fluxes in the Terrestrial Ecosystem: Summary for Policymakers.

[2] Alem, Y., Ruhinduka, D.R., Berck, P. and Bluestone, R. (2015) Liquidity Constraint, LPG Stoves and Charcoal Consumption-Evidence from a Randomised Controlled Trial. University of Gothenburg, Gothenburg.

[3] Naude, W. and Nagler, P. (2015) Industrialisation, Innovation and Inclusion. UNUMerit, Working Paper No. 2015-043.

[4] Romer, P.M. (1986) Increasing Returns and Long-Run Growth. Journal of Political Economy, 94, 1002-1037.

[5] United Nations Conference of Trade and Development (2017) The Role of Science, Technology and Innovation in Ensuring Food Security by 2030. Geneva.

[6] Ratti, C. (2016) Five Innovations That Could Transform Africa. World Economic Forum.

[7] Diop, M. (2017) Innovation in Africa. The World Bank, Washington DC. https://www.worldbank.org/en/news/speech/2017/11/30/innovation-in-africa

[8] Crosby, A.W. (2006) Children of the Sun: A History of Humanity's Unappeasable Appetite for Energy. W.W. Norton \& Company, Inc., New York.

[9] Goldenberg, J. (2001) Energy and Human Wellbeing. United Nations Development Programme, Human Development Report. http://hdr.undp.org/en/content/energy-and-human-well-being

[10] Najam, A. and Cleveland, C. (2008) Energy and Sustainable Development at Global Environmental Summits: An Evolving Agenda. https://www.researchgate.net/publication/226292687_Energy_and_Sustainable_Devel opment_at_Global_Environmental_Summits_An_Evolving_Agenda

[11] Matthews, W.G. and Zeissig, S.R. (2011) Residential Market for LPG. A Review of Experience of 20 Developing Countries. Houston International Business Corp. Energy and Environmental Policy Consultants 151 Moss Point, Friendswood. http://siteresources.worldbank.org/INTOGMC/Resources/Review_of_LPG_marke_in _20_countries_2011.pdf

[12] International Energy Agency (2017) Energy Access Outlook 2017. IEA, Paris. https://www.iea.org/publications/freepublications/publication/WEO2017SpecialRepor t_EnergyAccessOutlook.pdf

[13] Larsen, B. (2016) Benefits and Costs of Household Cooking Options for Air Pollution Control. Copenhagen Consensus Center, Copenhagen. https://www.copenhagenconsensus.com

[14] Bruce, G.N., Aunan, K. and Rehfuess, E.A. (2017) Liquefied Petroleum Gas as a Clean Cooking Fuel for Developing Countries. Implications for Climate, Forests, and Affordability.

[15] Kojima, M. (2011) The Role of Liquefied Petroleum Gas in Reducing Energy Poverty. Extractive Industries for Development Series \#25, WHO, Geneva.

[16] Puzzolo, E., Stanistreet, D., Pope, D., Bruce, N. and Rehfuess, E. (2013) Factors Influencing the Large-Scale Uptake by Households of Cleaner and More Efficient Household Energy Technologies. EPPI-Centre, Social Science Research Unit, Institute of Education, University of London, London.

[17] Vitali, F. (2012) Appropriate Solutions for Cooking Energy at Household Level in the Logone Valley. PhD Thesis, University of Brescia, Brescia.

[18] Heltberg, R. (2005) Factors Determining Household Fuel Choice in Guatemala. En- 
vironment and Development Economics, 10, 337-361.

https://doi.org/10.1017/S1355770X04001858

[19] Ekholm, T., Krey, V. and Pachauri, S. (2010) Determinants of Household Energy Consumption in India. Energy Policy, 38, 5696-5707. https://doi.org/10.1016/j.enpol.2010.05.017

[20] Benbekhaled, A., Gaz, S., El Guerchi, M., Evans, A., Ibirogba, A., Andrew Ford, A., Anderson, A., Edja, B., Cavagna, D., Adeshina, D., Ercüment Polat, A., Turkey, I., Batiste, E., France, S., Jarovsky, M. and Levallois, O. (2014) LPG and the Global Energy Transition. A Study on Behalf of the World LPG Association.

[21] Bisu, Y., Kuhe, A. and Iortye, H.A. (2016) Urban Household Cooking Energy Choice: An Example of Bauchi Metropolis, Nigeria. Energy, Sustainability and Society, 6, Article No. 15. https://doi.org/10.1186/s13705-016-0080-1

[22] United Republic of Tanzania (2015) The National Energy Policy. Ministry of Energy, Dar es Salaam.

[23] United Republic of Tanzania (2013) Energy Subsidy Policy—Revised Draft. Ministry of Energy and Minerals, Dar es Salaam. https://www.seforall.org/sites/default/files/TANZANIA_AA-Final.pdf

[24] Chidumayo, E. and Gumbo, D. (2013) The Environmental Impacts of Charcoal Production in Tropical Ecosystems of the World: A Synthesis. Energy for Sustainable Development, 71, 86-94. https://doi.org/10.1016/j.esd.2012.07.004

[25] United Republic of Tanzania (2014) Basic Demographic and Socio-Economic Profile Report. Tanzania Ministry of Finance, Dar es Salaam.

[26] Ishengoma, R.C. and Abdalah, J.M. (2016) Transforming Tanzania's Charcoal Sector Project. Technical Report 4. Charcoal Market Conditions in 2016 in Dar es Salaam and Morogoro.

[27] Global System for Mobile Communications Association (2018) KopaGas MobileEnabled Pay-as-You-Cook Service in Tanzania. GSMA Head Office, London.

[28] Google Map Data (2019) Kinondoni Map —Satellite Images of Kinondoni. http://www.maplandia.com/tanzania/dar-es-salaam/dar-es-salaam/kinondoni

[29] Kinondoni Municipal Council (2017) Municipal Profile. Dar es Salaam. https://www.bing.com/search?q=kinondoni+municipal+profile\&cvid=cbf21a4becec4 0e58d7ff70d533c8587\&aqs=edge..69i57j018.8249j0j1\&pglt=43\&FORM=ANNTA1 \&PC=U531

[30] Ubungo Municipal Council (2016) Municipal Profile. Dar es Salaam. http://www.ubungomc.go.tz/storage/app/uploads/public/5a8/fb2/621/5a8fb26213e009 69820372.pdf

[31] University of Southern California (2019) Research Guides. https://libguides.usc.edu/writingguide/researchdesigns

[32] Palaniappan, S., Asokan, R., Bharathwaj, S. and Sujaudeen, N. (2015) Automated Meter Reading-A Study. International Journal of Computer Applications, 116, 39-46. https://pdfs.semanticscholar.org/1f1f/f70512fd8eb09cc5256e0aa9a7494d719ec7.pd

[33] Uribe-Pérez, N., Hernández, L., de la Vega, D. and Angulo, I. (2016) State of the Art and Trends Review of Smart Metering in Electricity Grids. Applied Sciences, 6, 68. https://doi.org/10.3390/app6030068

[34] Koponen, P., Saco, L.D., Orchard, N., Vorisek, T., Parsons, J., Rochas, C., Morch, A.Z., Lopes, V. and Togeby, M. (2008) Definition of Smart Metering and Applications and Identification of Benefits. Work Package 2 State of Art, Deliverable 3 Project Contract: EIE/06/031/S12.448010-ESMA Version 1.1, 12 May 2008.

[35] Vadda, P. (2013) Smart Metering for Smart Electricity Consumption. Master Thesis, (Electrical Engineering) School of Computing, Blekinge Institute of Technology, Karlskrona.

[36] Global Alliance for Clean Cook Stove (2017) "Pay-as-You-Go" Technology to Boost Access to Cooking Fuel. Washington DC. https://cleancooking.org/binary-data/RESOURCE/file/000/000/578-1.pdf

[37] Hosier, R.H. and Dowd, J. (1987) Household Fuel Choice in Zimbabwe: An Empirical Test of the Energy Ladder. Resources and Energy, 9, 347-361. 
https://doi.org/10.1016/0165-0572(87)90003-X

[38] The Citizen (2020) And Here Comes Tanzania's Newest Billionaire.

[39] Africa Inc. (2020) Supply Chain and Logistics Expo. https://ceobusinessafrica.com/circle-gas-completes-a-us $25 \mathrm{~m}$-acquisition-of-kopagas-t echnology/?amp

[40] Sustainable Development Goal Fact Sheet (2015) Time for Global Action for People and Planet.

https://www.un.org/sustainabledevelopment/wp/content/uploads/2015/08/Factsheet_S ummit.pdf

[41] Hood, A.H. (2010) The Use of Liquefied Petroleum Gas (LPG) in Sudan. United Nations Environmental Programme.

[42] Labriet, M., Alfaro, O. and Bashin, M. (2015) Scaling Up Demand for LPG in Guatemala: Motivators, Barriers and Opportunities. Public Health Institute, Oakland.

[43] Hoffecker, E. (2018) Local Innovation: What It Is and Why It Matters for Developing Economies. D-Lab Working Papers: NDIR Working Paper 01. MIT D-Lab, Cambridge.

[44] Miguélez, E., Moreno, R. and Suriñach, J. (2010) Inventors on the Move: Tracing Inventors' Mobility and Its Spatial Distribution. Papers in Regional Science, 89, 251-274. https://doi.org/10.1111/j.1435-5957.2010.00280.x

[45] Africa Energy Year Book (2011) A Model for Clean Energy Innovation in Africa. The Power of Climate. 